\title{
Treatment-emergent adverse events after infusion of adherent stem cells: the MiSOT-I score for solid organ transplantation
}

Johannes Dillmann ${ }^{1}$, Felix C Popp ${ }^{1}$, Barbara Fillenberg ${ }^{1}$, Florian Zeman², Elke Eggenhofer ${ }^{1}$, Stefan Farkas ${ }^{1}$, Marcus N Scherer ${ }^{1}$, Michael Koller², Edward K Geissler ${ }^{1}$, Robert Deans ${ }^{3}$, Deborah Ladenheim ${ }^{3}$, Martin Loss ${ }^{1}$, Hans J Schlitt ${ }^{1}$ and Marc H Dahlke ${ }^{1 *}$

\begin{abstract}
Background: Cellular therapy after organ transplantation is emerging as an intriguing strategy to achieve dose reduction of classical immunosuppressive pharmacotherapy. Here, we introduce a new scoring system to assess treatment-emergent adverse events (TEAEs) of adherent stem cell therapies in the clinical setting of allogeneic liver transplantation (for example, the MiSOT-I trial Eudract CT: 2009-017795-25).

Methods: The score consists of three independent modalities (set of parameters) that focus on clinically relevant events early after intravenous or intraportal stem cell infusion: pulmonary toxicity, intraportal-infusional toxicity and systemic toxicity. For each modality, values between 0 (no TEAE) and 3 (severe TEAE) were defined. The score was validated retrospectively on a cohort of $n=187$ recipients of liver allografts not receiving investigational cell therapy between July 2004 and December 2010. These patients represent a control population for further trials. Score values were calculated for days 1, 4, and 10 after liver transplantation.
\end{abstract}

Results: Grade 3 events were most commonly related to the pulmonary system (3.5\% of study cohort on day 4). Almost no systemic-related TEAEs were observed during the study period. The relative frequency of grade 3 events never exceeded 5\% over all modalities and time points. A subgroup analysis for grade 3 patients provided no descriptors associated with severe TEAEs.

Conclusion: The MiSOT-I score provides an assessment tool to score specific adverse events that may occur after adherent stem cell therapy in the clinical setting of organ transplantation and is thus a helpful tool to conduct a safety study.

Keywords: Adherent adult stem cells, Mesenchymal stem cells, Multipotent adult progenitor cells, Solid organ transplantation, Immunotherapy, Scoring adverse events, Phase I trial

\section{Background}

The results of solid organ transplantation as definitive treatment for end-stage disease of the liver (for example, cirrhosis and metabolic decompensation) and other organs are clinically satisfactory [1]. However, the overall success of organ transplantation as a curative therapy is still hampered by the need for life-long immunosuppressive treatment of the recipient to control graft rejection.

\footnotetext{
*Correspondence: marc.dahlke@ukr.de

'Department of Surgery, University Hospital Regensburg, Franz Josef Strauss Allee 11, 93053 Regensburg, Germany

Full list of author information is available at the end of the article
}

Standard-of-care immunosuppressive pharmacotherapy has a variety of drug-specific unwanted effects, such as the neurotoxicity of tacrolimus or the renal toxicity of ciclosporin [2]. Moreover, immunosuppressants increase the recipient's risk of cancer [3] and opportunistic infections [4]. Immunomodulatory cellular therapy as an adjunct to classical pharmacotherapy has emerged as an intriguing strategy to achieve dose reductions of immunosuppressive drug therapy.

Multipotent adult progenitor cells (MAPCs) are bone marrow derived [5], adherent stem cells which are closely related to mesenchymal stem cells (MSC) [6],

\section{Biomed Central}


and have been shown to have immunosuppressive functions in vitro and in vivo [7]. MAPCs and MSCs effectively prolong allograft survival in small animal models when combined with otherwise subtherapeutic doses of suitable immunosuppressants, such as mycophenolate $[8,9]$. Building on this body of preclinical evidence, we have initiated a phase I study (MiSOT-I study, Eudract CT no. 2009-017795-25) to apply MAPCs after allogeneic liver transplantation (LTx) [10]. The primary endpoints of the MiSOT-I study will be safety and feasibility of MAPC infusions.

In the current paper, we introduce a scoring system designed to evaluate treatment-emergent adverse events (TEAEs) of intravenous and intraportal infusions of MAPCs after liver transplantation. Since similar events (mimicking 'toxicity') can also occur without cell therapy in LTx recipients, we validated the score in 187 recipients of liver allografts not receiving investigational cell therapy. We only focused on events that we anticipate to be specific for adherent stem cell therapy in this clinical setting. Hence, the current analysis outlines the background against which the toxicity of new cellular therapies has to be evaluated. The future objective of cell therapy after solid organ transplantation will be to establish the immunological efficacy of the cell product. Therefore, we also used the current analysis to establish a retrospective control group that will allow us to collect first evidence of the immunological efficacy of MAPC therapy after LTx.

\section{Methods}

\section{Patients}

One hundred and eighty-seven patients who had received an allogeneic liver graft in our tertiary referral center between July 2004 and December 2010 were included in this retrospective analysis. Recipients of living-related grafts, patients who received a secondary liver graft during the entire course of their disease, HIVpositive recipients, and patients older than 65 years or younger than 18 years were excluded from the analysis (Figure 1). We have obtained ethical approval for this retrospective analysis from the local ethics committee (Ethikkommission der Universität Regensburg, No. 10101-0244). Since patients data were analyzed in a pseudonymous fashion only, no informed consent was requested.

\section{Data collection}

All patients included were reviewed using a standardized score sheet that will also be part of the MiSOT-I case report form (Figure 2). Clinical information from the Eurotransplant online database was also included. Additionally, the time to the last rejection-free follow-up was recorded as an indicator for the efficacy of standard-of-
314 patients $(=100 \%)$ [total patient collective]

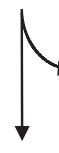

exclusion criteria 1 52 patients $(=16.6 \%)$

262 patientas $(=83.4 \%)$

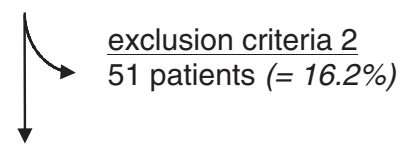

211 patients $(=67.2 \%)$

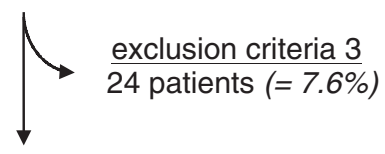

187 patients (59.6\%)

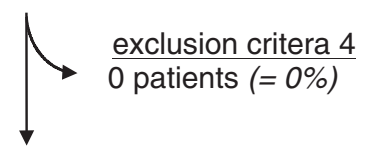

187 patients included

Figure 1 Study population and exclusion criteria. $n=187$ patients are included out of an initial patient collective of $n=314$.

care immunosuppression. All data collected were stored and computed using IBM SPSS 18.0 Statistics Software (SPSS, Chicago, IL, USA). Data consistency was checked by a secondary investigator (BF, MHD).

\section{Statistical methods}

Data analysis was carried out by a biostatistician (FZ). Proportions are presented as frequency counts and percentages, along with the corresponding 95\% confidence intervals (CI) following Wilson's method [11]. Continuous data are summarized as mean values and standard deviations. For comparison of two groups, Pearson's chi-square test was applied for categorical variables and the Mann-Whitney $U$-Test for continuous variables. Rejection-free survival times were estimated by KaplanMeier analysis, and distributions between groups were compared by the log-rank test. All reported $P$ values are two-sided, and a $P$ value of 0.05 was considered the threshold of statistical significance. Hazard ratios (HR) and corresponding 95\% CI were calculated and 


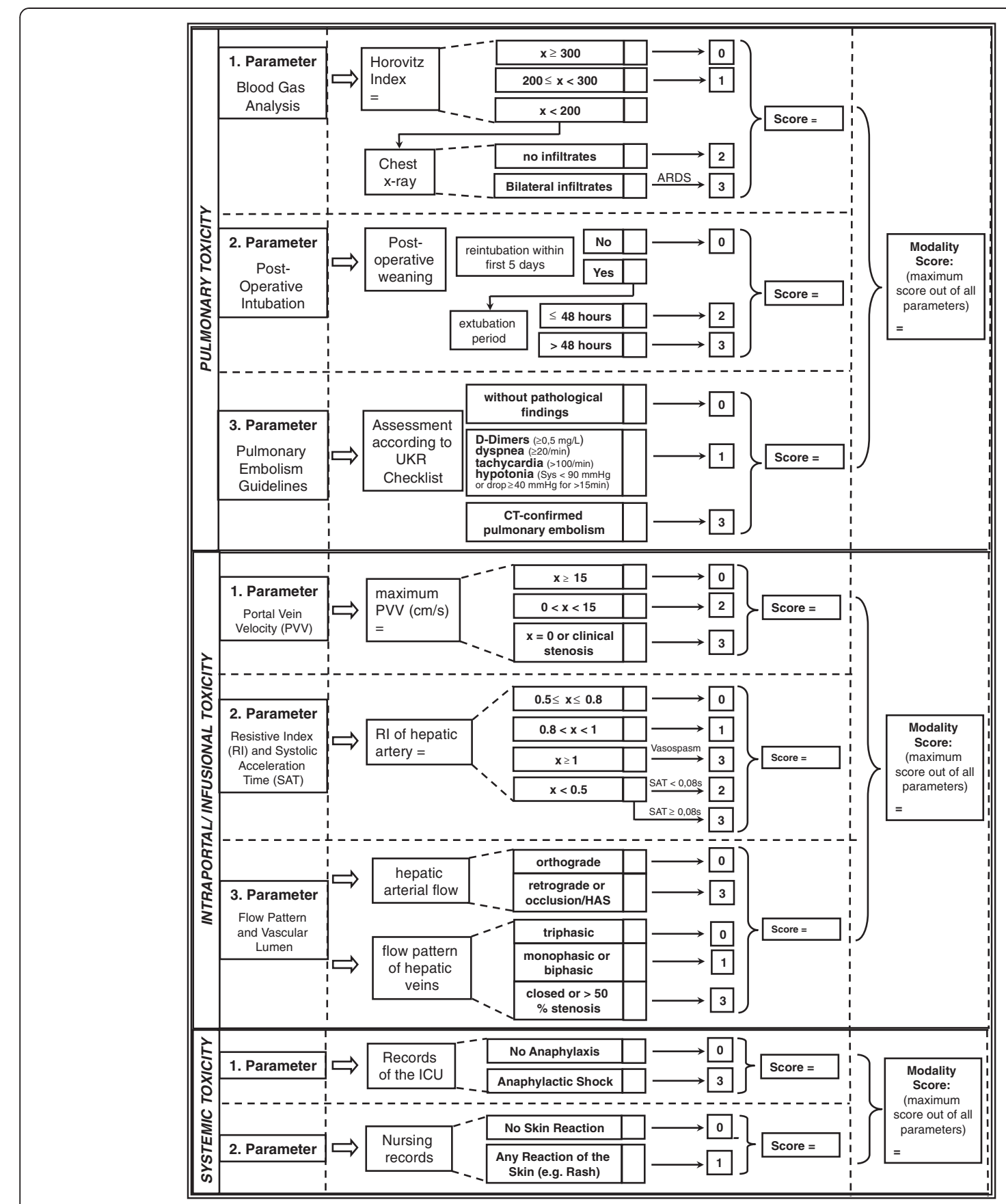

Figure 2 Outline of the MiSOT-I score. Every modality is defined by a set of parameters. Each parameter amounts to the designated score. The score values are not cumulative. Thus the maximum score in a set of parameters defines the score of that modality. ARDS, Acute respiratory distress syndrome; ICU, Intensive care unit; PW, Portal vein velocity; RI, Resistive index; SAT, Systolic acceleration time; UKR, University Hospital Regensburg.

considered statistically significant if the CI excluded 1.0. No adjustment for multiple testing was performed.

\section{MiSOT-I score}

The MiSOT-I score was designed as a high-barrier score that excludes clinical events that are clearly unacceptable TEAEs in phase I/II development of adherent stem cell products in patients after liver transplantation. Based on preclinical studies with adherent stem cell therapy $[12,13]$ and observations made in a variety of early trials with adherent stem cells in indications other than solid organ transplantation [14-16], we defined three independent modalities (set of parameters) to reflect potentially critical aspects of adherent stem cell therapy: 
pulmonary toxicity (first-pass after intravenous injection), intraportal/infusional toxicity (first-pass after intraportal infusion), and systemic toxicity (immune reaction after cell infusion).

For each of the parameters of the MiSOT-I score, values between 0 and 3 were defined (Figure 2). A score of 0 implies no TEAE. Scores of 1 and 2 stand for intermediate TEAEs, while a score of 3 indicates a clinically unacceptable severe TEAE. In the prospective analysis of the MiSOT-I trial, a score of 3 will be considered a dose-limiting toxicity event.

Score values within a set of parameters were not cumulated so that the maximum score in each set of parameters defined the total score for that modality. Thus, each patient received three independent scores. To assess the clinical course of each patient, toxicity scores were computed for day 1 (range of days, 0 to 1 ), day 4 (range of days, 2 to 6), and day 10 (range of days, 8 to 12$)$.

\section{Pulmonary toxicity}

Assessment of pulmonary toxicity was based on three parameters, that is, the Horovitz Quotient (HQ) $\left(\mathrm{FiO}_{2} /\right.$ $\mathrm{PaO}_{2}$ ), the postoperative weaning from mechanical ventilation, and pulmonary embolism.

A HQ above 300 was defined as a score of 0 , a HQ between 200 and 300 corresponded to a score of 1 , and a HQ below 200 triggered further assessment of a chest $\mathrm{X}$-ray for pulmonary infiltrations. Bilateral infiltrates as assessed by a staff radiologist corresponded to a score of 3 (equivalent to an acute respiratory distress syndrome), whereas the absence of such resulted in a score of 2 (equivalent to an acute lung injury) [17].

The course of postoperative weaning from mechanical ventilation was assessed as follows: Successful extubation without the need for reintubation within the first $48 \mathrm{~h}$ was assigned a score of $0[18,19]$. Reintubation within 48 $\mathrm{h}$ after extubation was assigned a score of 2 , and reintubation more than $48 \mathrm{~h}$ after extubation within the first 5 postoperative days was assigned a score of 3 .

The occurrence of CT-proven pulmonary emboli was assessed in accordance with European consensus guidelines [20]. A positive finding was defined as a score of 3 , whereas the constellation of elevated D-Dimers ( $\geq 0.5 \mathrm{mg} / \mathrm{L}$ ), dyspnea (tachypnea $\geq 20 / \mathrm{min}$ ), tachycardia $(>100 / \mathrm{min}$ ), and hypotonia (systolic blood pressure $<90 \mathrm{mmHg}$ or a pressure drop of $\geq 40 \mathrm{mmHg}$ for $>15 \mathrm{~min}$ ) was assigned a score of 1 .

\section{Intraportal/infusional toxicity}

The assessment of intraportal toxicity was based on hepatic duplex ultrasound results. The included parameters were as follows: the maximum portal venous velocity (PVV), the resistance index (RI) and systolic acceleration time (SAT) of the hepatic artery, and finally the flow pattern and patency of the hepatic vessels.

If the PVV was $\geq 15 \mathrm{~cm} / \mathrm{s}$ a score of 0 was assigned. A PVV between $0 \mathrm{~cm} / \mathrm{s}$ and $15 \mathrm{~cm} / \mathrm{s}$ resulted in a 2 , whereas a score of 3 was allocated in the case of portal venous occlusion (if a surgical problem was excluded: $\mathrm{PVV}=0 \mathrm{~cm} / \mathrm{s}$, coherent post-stenotic flow acceleration, and clinical judgment) $[21,22]$.

If the RI ranged between 0.5 and 0.8 a score of 0 was assigned. An RI above 0.8 but below 1 was given a score of 1. A RI $<0.5$ together with a SAT below $0.08 \mathrm{~s}$ resulted in a 2 , whereas a score of 3 was allocated in the case of hepatic arterial occlusion (if a surgical problem was excluded: $\mathrm{RI}<0.5$ together with a SAT $\geq 0.08 \mathrm{~s}$ [23], vasospasm indicated by a RI $\geq 1$ [24], and clinical judgment).

Orthograde arterial blood flow and an open triphasic flow pattern of the hepatic veins were given a score of 0 . Limited blood flow in the hepatic veins (monophasic or biphasic flow pattern without surgical impairment) [25] was assigned a score of 1 . A score of 3 was allocated in the case of retrograde arterial blood flow, or an occlusion of the hepatic veins ( $>50 \%$ stenosis without a surgical problem). Although Doppler analysis is prone to inter- and intra-observer error, it was considered the best available tool for the assessment of hepatic perfusion [26].

\section{Systemic toxicity}

The assessment of systemic toxicity was based on intensive care unit and nursing records. Any clinical finding implying an anaphylactic reaction was assigned a score of 3. Shock was defined by the need for vasopressor treatment or mechanical ventilation [27]. Any skin reaction was assigned a score of 1 . The absence of anaphylaxis or skin reactions corresponded to a score of 0 . A score value of 2 was not defined for this modality.

\section{Rejection analysis}

The future objective of cell therapy after solid organ transplantation will be to establish the immunological efficacy of the cell product. Therefore, we also used the current analysis to determine the liver graft rejectionfree survival of the patients in our study cohort after standard-of-care immunosuppressive treatment. These data will serve as a retrospective control group allowing us to collect any first evidence of the immunological efficacy of our cell therapy protocol.

We compared the rejection-rates of patients who received calcineurin inhibitors (ciclosporin A or tacrolimus) or sirolimus as their primary immusuppressive regimen (group $\mathrm{CNI}$ ) to the patients treated with $\mathrm{CNI}-$ free immunosuppression (group CNI-free). We only retrospectively analyzed primary immunosuppression 
after liver transplantation. Therefore, any secondary changes to the immunosuppressive regimens were not taken into account. Rejection-free survival time of liver grafts was calculated from the date of graft implantation to the date of acute graft rejection. We differentiated between the following observation periods: day 0 to 10 ; day 0 to 30; day 0 to 90 ; day 0 to 365 . Patients lost to follow-up and patients who died during the observation period were censored. For the primary rejection analysis, only biopsy-proven acute graft rejections or death from acute rejection were considered events. In a secondary rejection analysis, cortisone pulse therapy during the period on the intensive care unit was additionally considered an event for acute graft rejection.

\section{Results}

\section{Study cohort}

A total of 314 patients from our institutional database were included in this analysis (Figure 1). Patients who required a secondary liver graft in the course of their clinical follow-up were excluded from the study (52/314; $16.6 \%$ ), as were children below the age of 18 years or patients older than 65 years $(51 / 314 ; 16.2 \%)$, and patients who received a liver graft from a living donor (24/314; 7.6\%). A HIV-positive status was also considered an exclusion criterion, however there were no HIV-positive patients among the initial 314 patients. Ultimately, 187/314 (59.6\%) patients were included in the analysis; $72.7 \%$ of the study population were men. The mean age was 50.6 years (Table 1 ).

\section{Modality analysis}

All patients were reviewed using a standardized score sheet (Figure 2). For the assessment of pulmonary toxicity, data for $187 / 187$ patients $(100 \%)$ were available on day $1,85 / 187(45 \%)$ on day 4 , and $41 / 187(21.9 \%)$ on day 10. For intraportal/infusional toxicity, data were retrieved for $152 / 187$ patients $(81.3 \%)$ on day $1,113 / 187$ $(60.4 \%)$ on day 4 , and $77 / 187(41.2 \%)$ on day 10 . Finally, for systemic toxicity, data were available for all patients on days 1,4 , and 10 . Table 2 shows the score distribution for each of the three modalities on days 1,4 , and 10. At all time points examined, the majority of analyzed

Table 1 Baseline patient characteristics $(n=187)$

\begin{tabular}{lllll}
\hline & & $\boldsymbol{n}$ & $\%$ & \\
\hline Sex & & & & \\
\hline Male & 136 & 72.7 & \\
\hline Female & 51 & 27.3 & Maximum \\
\hline & Mean & SD & Minimum & 64.92 \\
\hline Age (years) & 50.64 & 9.78 & 19.75 &
\end{tabular}

Gender and age of the patient collective included ( $n=187)$. patients revealed no TEAEs. At no time did the frequency of severe TEAEs (grade 3) exceed 5\%.

Figure $3 \mathrm{~A}$ illustrates the distribution of pulmonary events. The highest relative frequency of grade 1 TEAEs $(15 / 41 ; 36.6 \%)$ was observed on day 10 , whereas grade 2 and 3 TEAEs were most frequently seen on day 4 $(15 / 85 ; 17.6 \%$ and $3 / 85 ; 3.5 \%$, respectively). The distribution of intraportal/infusional events is shown in Figure 3B. Grade 1 and 3 TEAEs were most frequent on day 1 (42/152; $27.6 \%$ and $3 / 152 ; 2 \%$, respectively), while grade 2 TEAEs occurred most often on day 10 (7/77; 9.1\%). Finally, Figure $3 \mathrm{C}$ outlines the distribution of systemic events. Grade 1 TEAEs occurred in $1.1 \%$ of patients $(2 / 187)$ on day 4 and $0.5 \%$ of patients $(1 / 187)$ on day 10 . A grade 3 event occurred on only one occasion, that is, on day 1 in one patient $(0.5 \%)$. All of the remaining patients revealed no systemicrelated TEAEs $(186 / 187 ; 99.5 \%$ on days 1 and 10 , $185 / 187 ; 98.9 \%$ on day 4$)$.

\section{Subgroup analysis for patients with grade 3 events}

We further analyzed the subgroup of 12 patients who developed clinically unacceptable severe TEAEs (grade 3 events) to identify clinical conditions typically associated with such events. None of the 12 patients attained a score of 3 in more than one modality. Moreover, no patient experienced grade 3 events on 2 different days within a single modality. The following clinical events were responsible for grade 3 TEAEs: one patient experienced a pulmonary embolism on day 1; two patients were reintubated within the first 5 postoperative days after an extubation period $>48 \mathrm{~h}$; three patients developed acute respiratory distress syndrome on day 1 and one on day 4; one patient had a portal venous occlusion on day 1; two patients experienced a hepatic arterial occlusion on day 1; one patient suffered an occlusion of the hepatic veins on day 10, and one patient had an anaphylactic shock on day 1 . To determine which patient characteristics are associated with severe TEAEs and to develop hypotheses for the early detection of these patients, the group of 12 patients with grade 3 TEAEs was compared with the remaining 175 patients. However, none of the parameters analyzed revealed a significant difference between the two groups (Table 3).

\section{Rejection-free survival}

For the assessment of the liver graft rejection-free survival, data were available for $185 / 187$ patients (98.9\%). One patient died prior to first immunosuppressive treatment. For the other patient, it was not possible to accurately determine the primary immunosuppression after LTx retrospectively. As secondary changes to the immunosuppressive regimen and special patient characteristics (for example, renal failure, high MELD scores) 
Table 2 Score distribution

\begin{tabular}{|c|c|c|c|c|c|c|c|c|c|c|}
\hline \multirow[t]{2}{*}{ Modality } & \multirow[t]{2}{*}{ Score } & \multicolumn{3}{|c|}{ Day 1} & \multicolumn{3}{|c|}{ Day 4} & \multicolumn{3}{|c|}{ Day 10} \\
\hline & & $n$ & $\%$ & $(95 \% \mathrm{Cl})$ & $n$ & $\%$ & $(95 \% \mathrm{Cl})$ & $n$ & $\%$ & $(95 \% \mathrm{Cl})$ \\
\hline \multirow[t]{5}{*}{ Pulmonary } & Total $n$ & 187 & & & 85 & & & 41 & & \\
\hline & 0 & 91 & 65.9 & $(57.7-73.3)$ & 47 & 55.3 & $(44.7-65.4)$ & 22 & 53.7 & $(38.7-67.9)$ \\
\hline & 1 & 31 & 22.5 & $(16.3-30.1)$ & 20 & 23.5 & $(15.8-33.6)$ & 15 & 36.6 & $(23.6-51.9)$ \\
\hline & 2 & 12 & 8.7 & $(5.0-14.6)$ & 15 & 17.6 & $(11.0-27.1)$ & 4 & 9.8 & $(3.9-22.5)$ \\
\hline & 3 & 4 & 2.9 & $(1.1-7.21)$ & 3 & 3.5 & $(1.2-9.9)$ & 0 & 0.0 & $(0.0-8.6)$ \\
\hline \multirow[t]{5}{*}{ Intraportal/Infusional } & Total $n$ & 152 & & & 113 & & & 77 & & \\
\hline & 0 & 98 & 64.5 & $(56.6-71.6)$ & 82 & 72.6 & $(63.7-79.9)$ & 59 & 76.6 & $(66.0-84.7)$ \\
\hline & 1 & 42 & 27.6 & $(21.1-35.2)$ & 25 & 22.1 & $(15.5-30.6)$ & 10 & 13.0 & $(7.2-22.3)$ \\
\hline & 2 & 9 & 5.9 & $(3.1-10.9)$ & 6 & 5.3 & $(2.5-11.1)$ & 7 & 9.1 & $(4.5-17.6)$ \\
\hline & 3 & 3 & 2.0 & $(0.07-5.6)$ & 0 & 0.0 & $(0.0-3.3)$ & 1 & 1.3 & $(0.2-7.0)$ \\
\hline \multirow[t]{4}{*}{ Systemic } & Total $n$ & 187 & & & 187 & & & 187 & & \\
\hline & 0 & 186 & 99.5 & $(97.0-99.9)$ & 185 & 98.9 & $(96.2-99.7)$ & 186 & 99.5 & $(97.0-99.9)$ \\
\hline & 1 & 0 & 0.0 & $(0.0-2.0)$ & 2 & 1.1 & $(0.29-3.82)$ & 1 & 0.5 & $(0.09-2.97)$ \\
\hline & 3 & 1 & 0.5 & $(0.09-2.97)$ & 0 & 0.0 & $(0.0-2.0)$ & 0 & 0.0 & $(0.0-2.0)$ \\
\hline
\end{tabular}

Relative frequency of each score value within the three independent modalities.

$\mathrm{Cl}$, Confidence interval.

were not considered, the calculated rejection rates cannot be considered to have prospective impact. However, as a best available retrospective group, these data will be valuable to establish any first efficacy of MAPC therapy.

Among the 129 patients of the CNI group, 94 (72.9\%) did not reject their grafts (biopsy-proven) and were thus rejection-free during a follow-up period of 365 days. Fifty-six patients were treated with CNI-free immunosuppression. These patients were mainly patients with particularly high MELD scores and pronounced renal impairment. Thirty-two of these patients $(57.1 \%)$ did not experience acute rejection during clinical follow-up (HR=1.96, 95\%CI: $(1.17 ; 3.30), \quad P=0.01)$. The total rejection-free survival of all patients regardless of immunosuppressive treatment (also including the two dropouts) was $67.4 \%(126 / 187)$ (Figure 4). In the early postoperative phase until day 10 , only $5 / 129$ (3.9\%) of the CNI-treated patients rejected their liver graft,
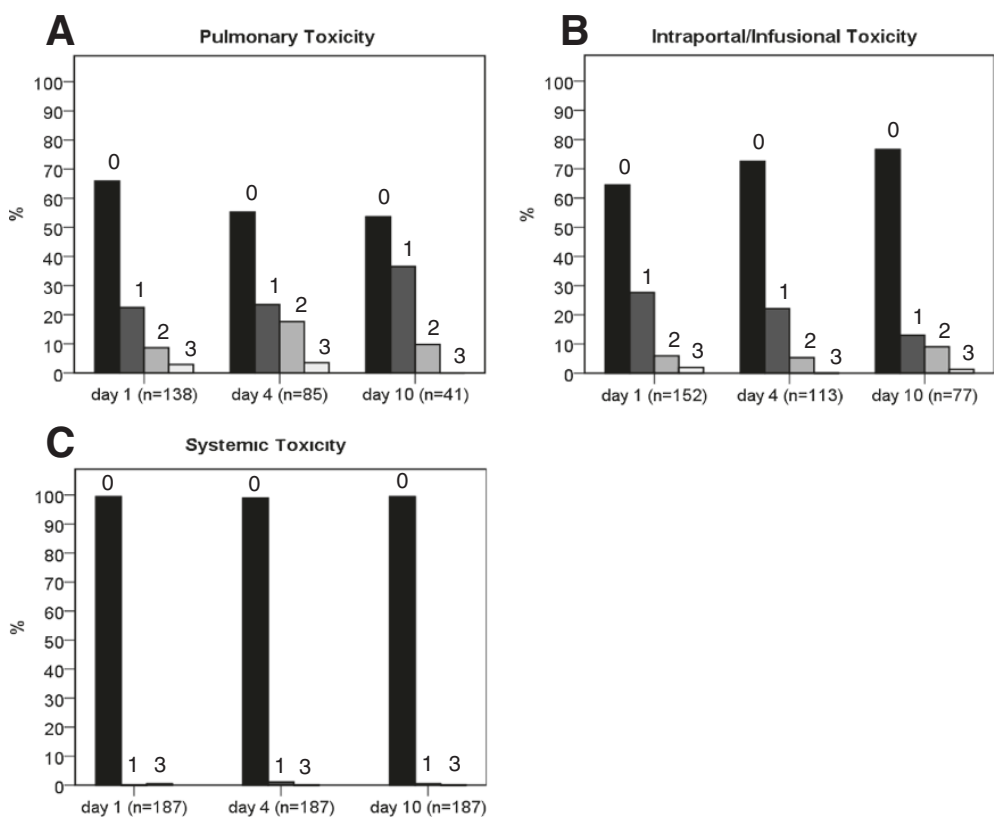

Figure 3 Score distribution. The relative frequency of each score value within the three independent modalities at days 1,4 , and 10 . The value above each bar indicates the respective score value. 
Table 3 Score 3 risk factor profile

\begin{tabular}{|c|c|c|c|c|c|c|}
\hline$n$ & Parameter & $n$ & Score $\neq 3$ & $n$ & Score $=3$ & $P$ \\
\hline 187 & Gender (\% male) & 175 & 71.4 & 12 & 91.7 & 0.128 \\
\hline 187 & Age (years) & 175 & $50.4(S D$ 9.9) & 12 & $53.8(S D$ 8.4) & 0.328 \\
\hline 175 & Cold ischemic period (Hours:Minutes) & 164 & 10:09 (SD 2:19) & 11 & 10:13 (SD 2:08) & 0.417 \\
\hline 183 & Immunosuppression (\% including CNI) & 171 & 65,7 & 12 & 83.33 & 0.342 \\
\hline 187 & Blood type (\% Type A) & 175 & 45.7 & 12 & 58.3 & 0.397 \\
\hline 187 & Blood type (\% Type B) & 175 & 10.3 & 12 & 8.3 & 0.829 \\
\hline 187 & Blood type (\% Type O) & 175 & 35.4 & 12 & 33.3 & 0.883 \\
\hline 187 & Alcoholic liver cirrhosis as cause for LTx (\%) & 175 & 36.6 & 12 & 33.3 & 0.822 \\
\hline 145 & Last measured Gamma GT of donor (U/L) & 137 & 55 (SD 54.7) & 8 & 73.75 (SD 58.2) & 0.343 \\
\hline 148 & Last measured Bilirubin (total) of donor $(\mu \mathrm{mol} / \mathrm{L})$ & 140 & 9.59 (SD 11.3) & 8 & 20.24 (SD 22.7) & 0.211 \\
\hline 135 & Last measured alcalic phosphatase of donor (IU/L) & 127 & 72.52 (SD 40.6) & 8 & $73.63(S D 27.6)$ & 0.734 \\
\hline
\end{tabular}

Statistical analysis of potential parameters correlating with the group of patients, who attained a score of 3 in one of the modalities.

SD, Standard deviation.

compared to $5 / 56(8.9 \%)$ patients in the CNI-free group $(\mathrm{HR}=2.41$, 95\%CI: $(0.70 ; 8.32), P=0.17)$. A comparison on day $30(12.4 \%$ vs. 33.9\%: $\mathrm{HR}=3.09,95 \% \mathrm{CI}:(1.59$; 6.01), $P<0.01)$ and day 90 (22.4\% vs. $42.9 \%$ : $(\mathrm{HR}=2.36$, 95\%CI: (1.37; 4.06), $P<0.01)$ emphasized the difference between the two patient collectives.
Finally, a secondary retrospective rejection analysis was performed that also considered the application of a cortisone pulse therapy during the ICU period as an indicator of suspected and treated acute graft rejection. This analysis revealed an additional eight cases (six CNI vs. two CNI-free) of non-biopsy-proven acute graft

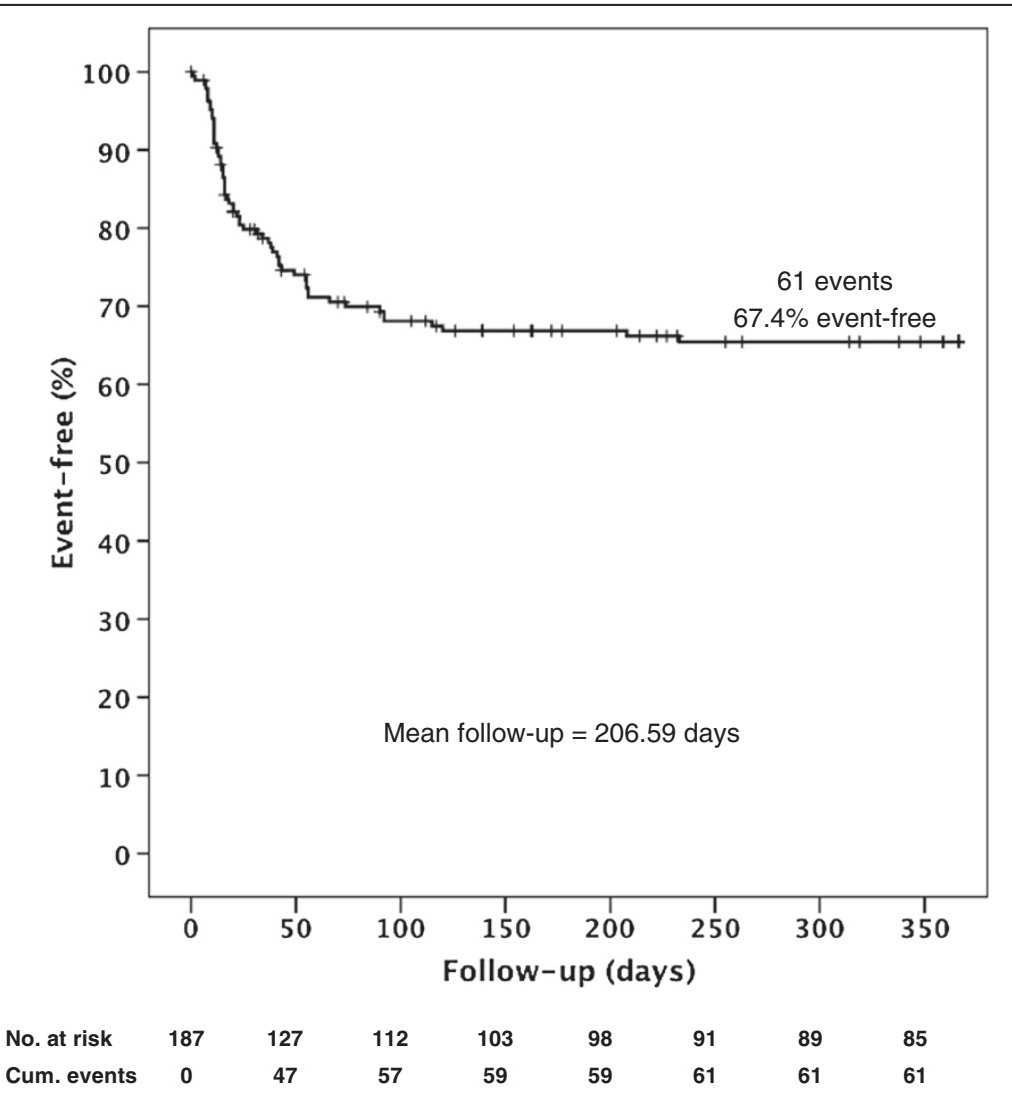

Figure 4 Kaplan-Meier curve of rejection-free graft survival 365 days after liver transplantation patients with biopsy-proven acute graft rejection or patients who died due to an acute rejection were considered events. Patients who died of other causes and patients lost to follow-up were censored. 
rejection with the cortisone bolus as the only indicator of an acute liver graft rejection. All of these events occurred within the first 30 postoperative days, increasing the rejection rate for the CNI group from $12.4 \%$ $(16 / 128)$ to $17.1 \%(22 / 129)$, and for the CNI-free group from $33.9 \%(19 / 56)$ to $37.5 \%(21 / 55)$.

\section{Discussion}

The objective of this study was to retrospectively validate a newly designed scoring system for TEAEs of liver-directed adherent stem cell therapy after liver transplantation (Figure 2). This score will be used in an approved phase-I study (MiSOT-I). The validation was conducted retrospectively in a cohort of 187 recipients of liver allografts who did not receive investigational cell therapy.

The majority of the study population showed no TEAEs (score 0) in accordance with the MiSOT-I score. This was expected, because the cut-off values of the score parameters were chosen to be a high barrier for clearly unacceptable clinical events in the further development of this and other stem cell therapies. For all modalities, the relative frequency of severe TEAEs (score 3) did not exceed 5\%. Previous studies looking at comparable complications after organ transplantation have shown rates of pulmonary embolism or acute respiratory distress syndrome of $0.37 \%$ [28] and 5.5\% [29], respectively. Also, portal venous occlusion, hepatic artery thrombosis, and hepatic vein stenosis, which accounted for most of the intraportal/infusional grade 3 TEAEs in our cohort, have reported rates of up to $2.6 \%, 3.2 \%$, and $1.5 \%$, respectively $[30,31]$.

By contrast, anaphylactic reactions (grade 3 parameter for systemic toxicity) are extremely rare in the clinical setting of solid organ transplantation, to our knowledge only one such case has been described in the published literature [32]. When comparing the three modalities, the highest relative frequency of a score of 3 was most often pulmonary-related (day $4=3.5 \%$ ). This is consistent with previous studies suggesting a high rate of pulmonary complications following orthotopic liver transplantation [29]. Systemic TEAEs were the least frequent, which can be explained by the general low incidence of postoperative anaphylaxis [32]. Thus, in view of the grade 3 events in our cohort, the results of this study confirm and further quantify the findings in the literature concerning pulmonary, hepatic, and systemic function after deceaseddonor liver transplantation.

A further subgroup analysis for patients with grade 3 events failed to provide a valuable hypothesis on which descriptors are associated with severe TEAEs (Table 3). Previous investigations have shown that patients with alcoholic cirrhosis achieve the same postoperative survival and complication rates as non-alcohol-related transplantations [33]. However, for all remaining parameters, numerous studies show that high age [34], male gender [35], non-A blood type of the recipient [35], low donor creatinine or bilirubine [36], a long cold ischemia time [37], and a high MELD score [38] all significantly correlate with an increased postoperative morbidity and mortality rate after liver transplantation. Hence, a correlation between grade 3 TEAEs and any of these parameters was expected but was not established in our cohort. A possible explanation for this discrepancy is the difference in size of the two compared subgroups ( $n=12$ vs. $n=175)$, although this was considered in the design of the statistical analysis. Another reason for this observation may be the choice of exclusion criteria (Figure 1), since most previous comparative studies included re-transplanted patients and patients above 65 years of age.

Biopsy-proven rejection-free survival after non-living related orthotopic liver transplantation was analyzed. Here, we grouped patients receiving CNI-free, sirolimusfree, bottom-up immunosuppression (as will be used in the MISOT-I study) against all other patients [39]. Patients who received ciclosporin A, tacrolimus, or sirolimus as their primary immunosuppression presented with a rejection-free graft survival rate of $72.9 \%$ after 365 days of follow-up (mean follow-up $=206.59$ days). The non-CNI, non-sirolimus, bottom-up group presented with rejection-free survival of $57.1 \%$ in comparison. Since time to biopsy-proven acute rejection will be a secondary endpoint of the MiSOT-I trial, the analysis of the rejection time in the present cohort can serve as a retrospective comparator, naturally with all bias and shortcomings of such an analysis.

Unavailability of data and low data consistency over the analyzed time period was the key limitation of this retrospective study. However, in the light of no other available data, this study will still be the most valuable comparator for MiSOT-I and other investigational phase I studies applying adherent stem cell therapies. No high-risk patients for the elected events could be identified from our present cohort and, therefore, we have no further means to exclude patient groups from MiSOT-I.

\section{Conclusion}

Whether adherent stem cell therapy is indeed inherently safe for all patients remains to be determined. In any case, the current score appears suitable to identify problems of adherent stem cell infusions, at least in the areas that we have included. Since the frequency of grade 3 TEAEs in this retrospective analysis was never higher than $5 \%$, we may assume a probability of $<5 \%$ that complications that are identified by this score are related to standard-of-care treatment after liver transplantation. Consequently, in the clinical setting of the 
MiSOT-I study, in which we plan to administer MAPCs to patients after liver transplantation, the probability of a single event being stem-cell-related is greater than 95\% and the probability of two consecutive events being stem-cell-related is greater than $99.75 \%$. Therefore, two grade 3 events have been defined as a stopping rule for MiSOT-I.

\section{Competing interests}

The authors declare no competing interests.

\section{Authors' contributions}

$J D$ and MHD designed the primary outlines of the MiSOT-I score with EE, $F C P, M L, S F, M N S$, and HJS. BF provided essential documents to realize this study. FZ and MK contributed substantially by ensuring statistical accuracy. FCP, EKG, HJS, RD, and DL supported the study with their knowledge and experience. All authors have read and approved the final manuscript.

\section{Acknowledgements}

MHD receives funds from Athersys and Novartis to conduct the MISOT-I study.

\section{Author details}

'Department of Surgery, University Hospital Regensburg, Franz Josef Strauss Allee 11, 93053 Regensburg, Germany. ${ }^{2}$ Center for Clinical Studies, University Hospital Regensburg, Regensburg, Germany. ${ }^{3}$ Athersys Inc., Cleveland, $\mathrm{OH}$, USA.

Received: 30 April 2012 Accepted: 31 October 2012 Published: 15 November 2012

\section{References}

1. Dutkowski P, Oberkofler CE, Béchir M, Müllhaupt B, Geier A, Raptis DA, Clavien PA: The model for end-stage liver disease allocation system for liver transplantation saves lives, but increases morbidity and cost: a prospective outcome analysis. Liver Transp/ 2011, 17:674-684.

2. Cattaneo D, Perico N, Gaspari F, Remuzzi G: Nephrotoxic aspects of cyclosporine. Transplant Proc 2004, 36:234S-239S.

3. Vajdic CM, van Leeuwen MT: Cancer incidence and risk factors after solid organ transplantation. Int J Cancer 2009, 125:1747-1754.

4. Fulginiti VA, Scribner R, Groth CG, Putnam CW, Brettschneider L, Gilbert S, Porter KA, Starzl TE: Infections in recipients of liver homografts. N Engl J Med 1968, 279:619-626.

5. Jiang $Y$, Jahagirdar BN, Reinhardt RL, Schwartz RE, Keene CD, Ortiz- Gonzalez XR, Reyes M, Lenvik T, Lund T, Blackstad M, Du J, Aldrich S, Lisberg A, Low WC, Largaespada DA, Verfaillie CM: Pluripotency of mesenchymal stem cells derived from adult marrow. Nature 2002, 418:41-49.

6. Reyes M, Verfaillie CM: Characterization of multipotent adult progenitor cells, a subpopulation of mesenchymal stem cells. Ann N Y Acad Sci 2001, 938:231-233. discussion 233-235.

7. English K, French A, Wood KJ: Mesenchymal stromal cells: facilitators of successful transplantation? Cell Stem Cell 2010, 7:431-442.

8. Popp FC, Eggenhofer E, Renner P, Slowik P, Lang SA, Kaspar H, Geissler EK, Piso P, Schlitt HJ, Dahlke MH: Mesenchymal stem cells can induce longterm acceptance of solid organ allografts in synergy with low- dose mycophenolate. Transpl Immunol 2008, 20:55-60.

9. Ge W, Jiang J, Baroja ML, Arp J, Zassoko R, Liu W, Bartholomew A, Garcia B, Wang $\mathrm{H}$ : Infusion of mesenchymal stem cells and rapamycin synergize to attenuate alloimmune responses and promote cardiac allograft tolerance. Am J Transplant 2009, 9:1760-1772.

10. Popp FC, Fillenberg B, Eggenhofer E, Renner P, Dillmann J, Benseler V, Schnitzbauer AA, Hutchinson J, Deans R, Ladenheim D, Graveen C, Zeman F, Koller M, Hoogduijn MJ, Geissler EK, Schlitt HJ, Dahlke MH: Study protocol: Safety and feasibility of third-party multipotent adult progenitor cells for immunomodulation therapy after liver transplantation-a phase I study (MISOT-I). J Trans Med 2011, 9:124

11. Newcombe RG: Two-sided confidence intervals for the single proportion: comparison of seven methods. Stat Med 1998, 17:857-872.
12. Ramot $Y$, Steiner M, Morad V, Leibovitch S, Amouyal N, Cesta MF, Nyska A: Pulmonary thrombosis in the mouse following intravenous administration of quantum dot-labeled mesenchymal cells. Nanitoxicology 2010, 4:98-105.

13. Furlani D, Ugurlucan M, Ong L, Bieback K, Pittermann E, Westien I, Wang W, Yerebakan C, Li W, Gaebel R, Li RK, Vollmar B, Steinhoff G, Ma N: Is the intravascular administration of mesenchymal stem cells safe? Mesenchymal stem cells and intravital microscopy. Microvasc Res 2009, 77:370-376

14. Dimomeletis I, Deindl E, Zaruba M, Groebner M, Zahler S, Laslo SM, David R, Kostin S, Deutsch MA, Assmann G, Mueller-Hoecker J, Feuring-Buske M, Franz WM: Assessment of human MAPCs for stem cell transplantation and cardiac regeneration after myocardial infarction in SCID mice. Exp Hematol 2010, 38:1105-1114.

15. Trounson A, Thakar RG, Lomax G, Gibbons D: Clinical trials for stem cell therapies. BMC Med 2011, 10:9-52.

16. Gonsalves A, Carrier M, Wells PS, McDiarmid SA, Huebsch LB, Allan DS: Incidence of symptomatic venous thromboembolism following hematopoietic stem cell transplantation. J Thromb Haemost 2008, 6:1468-1473.

17. Bernard G, Artigas A, Brigham K, Carlet J, Falke K, Hudson L, Lamy M, Legall J, Morris A, Spragg R: The American-European Consensus Conference on ARDS. Definitions, mechanisms, relevant outcomes, and clinical trial coordination. Am J Respir Crit Care Med 1994, 149:818-824.

18. Faenza S, Ravaglia MS, Cimatti M, Dante A, Spedicato S, Morselli Labate AM: Analysis of the causal factors of prolonged mechanical ventilation after orthotopic liver transplant. Transplant Proc 2006, 38:1131-1134.

19. Skurzak S, Stratta C, Schellino MM, Fop F, Andruetto P, Gallo M, Rampa P, Crucitti M, Zabatta D, Panio A, Cerutti E: Extubation score in the operating room after liver transplantation. Acta Anaesthesiol Scand 2010, 54:970-978.

20. Torbicki A, Perrier A, Konstantinides S, Agnelli G, Galie N, Pruszczyk P, Bengel F, Brady AJ, Ferreira D, Janssens U, Klepetko W, Mayer E, Remy-Jardin M, Bassand JP, ESC Committee for Practice Guidelines (CPG): Guidelines on the diagnosis and management of acute pulmonary embolism: the Task Force for the Diagnosis and Management of Acute Pulmonary Embolism of the European Society of Cardiology (ESC). Eur Heart J 2008, 29:2276-2315

21. Mullan CP, Siewert B, Kane RA, Sheiman RG: Can Doppler sonography discern between hemodynamically significant and insignificant portal vein stenosis after adult liver transplantation? AJR Am J Roentgenol 2010, 195:1438-1443.

22. Nakanishi S, Shiraki K, Yamamoto K, Saitou Y, Ohmori S, Nakano T, Mizuno S, Tabata M, Yamagiwa K, Yokoi H, Isaji S, Uemoto S: Early graft hemodynamics in living related liver transplantation evaluated by Doppler ultrasonography. Int J Mol Med 2004, 14:265-269.

23. Dodd GD 3rd, Memel DS, Zajko AB, Baron RL, Santaguida LA: Hepatic artery stenosis and thrombosis in transplant recipients: Doppler diagnosis with resistive index and systolic acceleration time. Radiology 1994, 192:657-661.

24. Chen W, Facciuto ME, Rocca JP, Marvin MR, Sheiner PA, Rachlin S, Rodriguez MI: Doppler ultrasonographic findings on hepatic arterial vasospasms early after liver transplantation. J Ultrasound Med 2006, 25:631-638.

25. Ko EY, Kim TK, Kim PN, Kim AY, Ha HK, Lee MG: Hepatic vein stenosis after living donor liver transplantation: evaluation with Doppler US. Radiology 2003, 229:806-810.

26. Tamsel S, Demirpolat G, Killi R, Aydin U, Kilic M, Zeytunlu M, Parildar M, Oran I, Ucar H: Vascular complications after liver transplantation: evaluation with Doppler US. Abdom Imaging 2007, 32:339-347.

27. Sampson HA, Muñoz-Furlong A, Campbell RL, Adkinson NF Jr, Bock SA, Branum A, Brown SG, Camargo CA Jr, Cydulka R, Galli SJ, Gidudu J, Gruchalla RS, Harlor AD Jr, Hepner DL, Lewis LM, Lieberman PL, Metcalfe DD, O'Connor R, Muraro A, Rudman A, Schmitt C, Scherrer D, Simons FE, Thomas S, Wood JP, Decker WW: Second symposium on the definition and management of anaphylaxis: Summary report--Second National Institute of Allergy and Infectious Disease/Food Allergy and Anaphylaxis Network symposium. Ann Emerg Med 2006, 47:373-380.

28. Cherian TP, Chiu K, Gunson B, Bramhall SR, Mayer D, Mirza DF, Buckels JA: Pulmonary thromboembolism in liver transplantation: a retrospective review of the first 25 years. Transpl Int 2010, 23:1113-1119.

29. Li SR, Shen N, Hei ZQ: Early risk factors of acute lung injury following orthotopic liver transplantation. Zhonghua Yi Xue Za Zhi 2008, 88:3049-3052 
30. Pareja E, Cortes M, Navarro R, Sanjuan F, López R, Mir J: Vascular complications after orthotopic liver transplantation: hepatic artery thrombosis. Transplant Proc 2010, 42:2970-2972.

31. Wu L, Zhang J, Guo Z, Tai Q, He X, Ju W, Wang D, Zhu X, Ma Y, Wang G, Hu A: Hepatic artery thrombosis after orthotopic liver transplant: a review of the same institute 5 years later. Exp Clin Transplant 2011, 9:191-196.

32. Andersona $A$, Eilersa $H$, Spencer Yost $C$ : Anaphylaxis complicating graft reperfusion during orthotopic liver transplantation: a case report. Transplant Proc 2010, 42:1967-1969.

33. Jaeck D, Fratte S, Boudjema K, Ellero B, Woehl-Jaegle ML, Vanlemmens C, Altier M, Duclos B, Vetter D, Bachellier P: Comparative study of results of hepatic transplantation between 2 groups of patients: alcoholic cirrhosis versus non-alcoholic cirrhosis. Chirurgie 1993-1994, 119:569-573.

34. Weismüller TJ, Prokein J, Becker T, Barg-Hock H, Klempnauer J, Manns MP, Strassburg CP: Prediction of survival after liver transplantation by pre-transplant parameters. Scand J Gastroenterol 2008, 43:736-746.

35. Matinlauri IH, Nurminen MM, Höckerstedt KA, Isoniemi HM: Risk factors predicting survival of liver transplantation. Transplant Proc 2005, 37:1155-1160

36. Sumskiene J, Kupcinskas L, Pundzius J, Sumskas L: Prognostic factors for short and long-term survival in patients selected for liver transplantation. Medicina (Kaunas) 2005, 41:39-46.

37. Totsuka E, Fung JJ, Hakamada K, Ohashi M, Takahashi K, Nakai M, Morohashi S, Morohashi H, Kimura N, Nishimura A, Ishizawa Y, Ono H, Narumi S, Sasak $\mathrm{M}$ : Synergistic effect of cold and warm ischemia time on postoperative graft function and outcome in human liver transplantation. Transplant Proc 2004, 36:1955-1958.

38. Cholongitas E, Marelli L, Shusang V, Senzolo M, Rolles K, Patch D, Burroughs AK: A systematic review of the performance of the model for end-stage liver disease (MELD) in the setting of liver transplantation. Liver Transpl 2006, 12:1049-1061.

39. Goralczyk AD, Schnitzbauer A, Tsui TY, Ramadori G, Lorf T, Obed A: A therapeutic exploratory study to determine the efficacy and safety of calcineurin-inhibitor-free de-novo immunosuppression after liver transplantation: CILT. BMC Surg 2010, 10:15.

doi:10.1186/1745-6215-13-211

Cite this article as: Dillmann et al:: Treatment-emergent adverse events after infusion of adherent stem cells: the MiSOT-I score for solid organ transplantation. Trials 2012 13:211.

\section{Submit your next manuscript to BioMed Central and take full advantage of:}

- Convenient online submission

- Thorough peer review

- No space constraints or color figure charges

- Immediate publication on acceptance

- Inclusion in PubMed, CAS, Scopus and Google Scholar

- Research which is freely available for redistribution 